\title{
Qual Educação para os Direitos Humanos?
}

\author{
Jardel Casanova Daneli \\ Mestrando em Direitos Humanos na Universidade do \\ Minho. Bacharel em Direito pela Faculdade Meridional - \\ Imed. Advogado. jardel_casanova@hotmail.com
}

\section{Sérgio Ricardo Fernandes de Aquino}

Doutor e mestre em Ciência Jurídica pela Universidade do Vale do Itajaí - Univali. Professor permanente do Programa de Pós-Graduação Stricto Sensu - Mestrado em Direito do Complexo de Ensino Superior Meridional - Imed. Professor do curso de Direito da Faculdade Meridional - Imed. Pesquisador da Faculdade Meridional. Coordenador do Grupo de Pesquisa: Ética, Cidadania e Sustentabilidade. Membro do Grupo de Pesquisa: "Modernidade, Pós-Modernidade e Pensamento Complexo", "Multiculturalismo e Pluralismo Jurídico" e "Transnacionalismo e circulação de modelos jurídicos". Líder do Centro brasileiro de pesquisa sobre Amartya Sen: interfaces com direito, políticas de desenvolvimento e democracia. Membro associado do Conselho Nacional de Pós-Graduação em Direito - Conpedi e da Associação Brasileira do Ensino de Direito - Abedi. Passo Fundo. RS. Brasil. sergiorfaquino@gmail.com

\section{Resumo:}

Educar para os Direitos Humanos: eis uma genuína aposta para o esclarecimento de nossas relações humanas no globo. 0 discurso desses direitos, entretanto, se torna vazio de significados quando a educação deforma as pessoas e não oportuniza o reconhecimento das diferenças como pressuposto fundamental à manutenção do convívio sadio e pacíficos entre elas. 0 Objetivo Geral deste estudo 
é determinar como a educação para os direitos Humanos precisa esclarecer o nosso vínculo antropológico comum para ampliar e consolidar o convívio amistoso global. 0 método de abordagem utilizado foi o dedutivo. Como parte das conclusões, verifica-se que a educação não pretende "salvar" ninguém, tampouco os referidos direitos, mas, pela interação e instrução, é possível criar cenários mais pacíficos, nos quais se identifique o que é o bem comum.

Palavras-chave: Direitos Humanos. Educação. Realidade. Razão Sensível.

\title{
Wich Education For Human Rights?
}

\begin{abstract}
:
An education for Human Rights: that is a genuine commitment to clarify our human relations on the globe. However, the discourse of these rights becomes empty of meaning when that act deforms people and not favors the recognition of differences as a fundamental prerequisite to maintain healthy and peaceful coexistence between people. The main objective of this study is to determine how the Education for Human Rights needs to explain our anthropological's common link to expand and consolidate an overall friendly living. The approach method was deductive. As part of our findings, it appears that education is not intended to "save" anyone, neither those rights, but the interaction and instruction you can create more peaceful scenarios which can identify what the common good.
\end{abstract}

Keywords: Human Rights. Education. Reality. Sensitive Reason.

\section{Sumário}

1 Introdução. 2 Educação para os Direitos Humanos: "pior para a realidade". 2.1 Luís Alberto Warat e a erudição vazia da doutrina. 3 Humanização dos Direitos Humanos. 4 Educação, Direitos Humanos e Sensibilidade Jurídica: por uma democracia utópica e barroca. 5 Conclusão. 6 Referências. 


\section{INTRODUÇÃO}

Warat, ao pensar o tema dos Direitos Humanos, afirmou: “[...]. Já dissemos que sem alteridade toda fala dos Direitos humanos termina em piada ou drama" ${ }^{1}$. Observa-se que significativa parte das faculdades de Direito não promove a autonomia do sujeito, tampouco estimula a descoberta histórica dos Direitos Humanos, ou, sequer, compreende a importância das diferenças culturais como pressuposto de eficácia desses direitos para a nossa perene humanização.

Não é possível, nem viável, que os Direitos Humanos cumpram seus objetivos se não houver pessoas racionais e sensíveis que se indignam com as misérias humanas. Não se trata de um discurso normativo, que tem a pretensão de "salvar o mundo". Ao contrário, é a vida de todos os dias que se torna o espaço criador dos significados de paz e concórdia entre os povos descrito pelos Direitos Humanos.

Por esse motivo, e para iniciar o debate proposto neste artigo, formula-se a seguinte indagação, a qual será o problema de pesquisa: É possível educar as pessoas para os direitos humanos se as Faculdades de Direito aniquilam ou ignoram o estímulo para uma Razão Sensível2?

\footnotetext{
${ }^{1}$ WARAT, Luis Alberto. A rua grita Dionísio! direitos humanos de alteridade, surrealismo e cartografia. Tradução de Vívian Alves de Assis, Julio Cesar Marcellino Júnior e Alexandre Morais da Rosa. Rio de Janeiro: Lúmen Juris, 2010, p. 118.

${ }^{2}$ A expressão denota a necessidade de se reconhecer a coerência própria manifestada pela vida, no seu sentido mais amplo, que nem sempre é exaurida - tampouco reconhecida - pela Razão Lógica. De modo complementar, utiliza-se, ainda, Razão Interna ou Razão Seminal. Nas palavras de Maffesoli (2008, p. 58), “[...] Trata-se de algo que permanece ou, melhor, preexiste no coração de todo homem antes de qualquer construção intelectual. É propriamente isto que chamarei 'razão interna' de todas as coisas. Razão esta que é tanto uma constante, de certo modo uma estrutura antropológica, quanto, ao mesmo tempo, só se atualiza, se realiza, neste ou naquele momento particular. Para dizer o mesmo em outras palavras, trata-se de uma racionalidade de fundo que se exprime em pequenas razões momentâneas".
} 
A hipótese inicial para essa pergunta é negativa, pois a educação se torna o espaço do diálogo, do movimento na direção ao Outro, por se compreender como as diferenças se tornam indispensáveis ao aperfeiçoamento histórico de nossas subjetividades. Quando as Faculdades de Direito se preocupam mais com os procedimentos em detrimento às pessoas e suas necessidades - sejam materiais emocionais ou espirituais - verifica-se o acentuado desserviço prestado aos seres humanos na promoção do convívio amistoso global. Ignoram-se, a partir desse argumento, os aspectos estéticos de uma vida comum democrática como condição para a mediação dos conflitos humanos.

Diante do atual cenário da educação no Brasil e ante as práticas voltadas para os Direitos Humanos, busca-se, por meio do presente artigo, provocar o leitor ou leitora para a reflexão quanto à educação direcionada para os Direitos Humanos no sentido de elaborar os possíveis caminhos a serem trilhados na consolidação de uma Sociedade ${ }^{3}$ mais justa e democrática.

É a partir desse argumento que se torna possível definir o objetivo geral: determinar como a educação para os direitos humanos precisa esclarecer o nosso vínculo antropológico comum para ampliar e consolidar o convívio amistoso global.

Os objetivos específicos, a fim de se viabilizar a finalidade principal deste estudo podem ser descritos nos seguintes tópicos: a) identificar como a educação precisa favorecer a compreensão acerca dos direitos humanos; b) averiguar as deformações causadas pelo excesso de zelo no pensamento lógico e procedimental das faculdades de Direito; c) reco-

\footnotetext{
${ }^{3}$ Segundo Dias (2010, p. 487): "A sociedade, enquanto fenômeno humano, decorre da associação de homens, da vida em comum, fundada na mesma origem, nos mesmos usos, costumes, valores, cultura e história. Constitui-se sociedade no e pelo fluxo das necessidades e potencialidades da vida humana; o que implica tanto a experiência da solidariedade, do cuidado, quanto da oposição, da conflitividade. Organização e caos são pólos complementares de um mesmo movimento - dialético - que dá dinamismo à vida da sociedade”.
} 
nhecer como as relações humanas se tornam mais sadias e fraternas na medida em que, no espaço do cotidiano, se empreendem atitudes que fomentam o bem comum. ${ }^{4}$

O esforço educacional destinado ao esclarecimento e importância dos direitos precisa estimular o ser humano ético e estetizado. Ambos são constituídos por valores morais imprescindíveis para a instauração de relações humanas solidárias. O primeiro é vetor de orientação para o agir prudencial diante do Outro sem que haja o conflito imediato pelas diferenças. O segundo refere-se à sensação causada pela ação ética, pois se estabelecem cenários harmônicos, pacíficos e agradáveis ao convívio. Trata-se de uma autêntica obra de arte ao estilo barroco, ${ }^{5}$ ou seja, a educação para os direitos humanos fomenta a estética da convivência. ${ }^{6}$

\footnotetext{
4 "O bem comum pressupõe o respeito pela pessoa humana enquanto tal, com direitos fundamentais e inalienáveis orientados para o seu desenvolvimento integral. Exige também os dispositivos de bem-estar e segurança social e o desenvolvimento dos vários grupos intermédios, aplicando o princípio da subsidiariedade. Entre tais grupos, destaca-se de forma especial a família enquanto célula basilar da sociedade. Por fim, o bem comum requer a paz social, isto é, a estabilidade e a segurança de uma certa ordem, que não se realiza sem uma atenção particular à justiça distributiva, cuja violação gera sempre violência. Toda a sociedade - e, nela, especialmente o Estado - tem obrigação de defender e promover o bem comum. Nas condições atuais da sociedade mundial, onde há tantas desigualdades e são cada vez mais numerosas as pessoas descartadas, privadas dos direitos humanos fundamentais, o princípio do bem comum torna-se imediatamente, como consequência lógica e inevitável, um apelo à solidariedade e uma opção preferencial pelos mais pobres. [...] Basta observar a realidade para compreender que, hoje, esta opção é uma exigência ética fundamental para a efetiva realização do bem comum” (FRANCISCO, 2015, p. 95).

5 “[...] não se pode analisar o barroco a partir de uma clássica instrumentação teórica, colocando em ação a simples causalidade, o linearismo ou outras formas de determinismo. É justamente para tornar a complexidade do uno múltipla que propus [...] substituir o conceito de unidade pela noção medieval de unicidade” (MAFFESOLI, 2005, p. 188).

${ }^{6}$ Sob o ângulo da Política Jurídica, a categoria denota sensação de "[...] harmonia e beleza que rescende dos atos de convívio social que se apóiam na Ética e no respeito à dignidade humana. Assim, podemos considerar como um dos fins mediatos da Política Jurídica a criação normativa de um ambiente de relações fundadas na Ética que venham a ensejar o belo na convivência social, em atendimento a necessidades espirituais latentes em todo ser humano [...]” (MELO, 2000, p. 37-38).
} 
Escolheu-se como método de abordagem para esta pesquisa o dedutivo, ${ }^{7}$ cuja premissa maior é a necessidade de educação como pressuposto de desenvolvimento e esclarecimento acerca da viabilidade histórica dos Direitos Humanos (premissa menor). As técnicas utilizadas, por outro lado, serão a Pesquisa Bibliográfica, ${ }^{8}$ a Categoria ${ }^{9}$ e o Conceito Operacional. ${ }^{10}$

Restabelecer uma relação dialogal entre educação e realidade desde que a segunda palavra não tenha reinterpretações tendenciosas e a primeira seja constituída pela capacidade de sensibilizar e humanizar, de forma que permita ao acadêmico tornar-se agente na busca pela consolidação de um novo cenário social - se torna o desafio do século 21. Os aspectos estéticos da vida cotidiana expressos como umas obras de arte indicam um caminho para a necessidade da educação dos Direitos Humanos, cuja inquietude fomentada pela alteridade se materializa com atitudes de indignação contra o injusto.

\section{EDUCAÇÃO PARA OS DIREITOS HUMANOS: "PIOR PARA A REALIDADE"}

A Educação, bem como o Ensino de qualidade, nas palavras de Bittar (2011, p. 48), é aquela que aproxima o sentir do pensar crítico e os intensifica quando penetra “[...] pelos poros, gerando angústia, medo,

\footnotetext{
${ }_{7}^{7}$ Para Pasold, trata-se da “[...] base lógica da dinâmica da Pesquisa Científica que consiste em estabelecer uma formulação geral e, em seguida, buscar as partes do fenômeno de modo a sustentar a formulação geral” (2011, p. 205).

8 “[...] Técnica de investigação em livros, repertórios jurisprudenciais e coletâneas legais" (PASOLD, 2011, p. 207).

9 “[...] palavra ou expressão estratégica à elaboração e/ou expressão de uma idéia" (PASOLD, 2011, p. 25). Grifos originais da obra em estudo. Toda Categoria que aparece neste estudo será destacada com letra maiúscula.

${ }^{10}$ Reitera-se, conforme Pasold (2011, p. 37): “[...] uma definição para uma palavra ou expressão, com o desejo de que tal definição seja aceita para os efeitos das idéias que expomos [...]”. Grifos originais da obra em estudo.
} 
dúvida, revolta, mobilização, reflexão, interação, opiniões exaltadas, espanto, descoberta, curiosidade, anseios, esperanças...”.No momento que essa condição acontece, os alunos e alunas tornam-se envolvidos pelas diversas dimensões do conhecimento, despertando, assim, os seus próprios sentidos à percepção do real, caminhando à reconquista da subjetividade autônoma. ${ }^{11}$

Quando a sala de aula transcende seus limites estruturais e transforma-se em um laboratório de experiências pedagógicas, de esclarecimento sobre a importância da teoria junto ao mundo da vida, permite ao indivíduo não somente a memorização do conteúdo aprendido, mas provoca sua criatividade, suas capacidades, as quais, muitas vezes, estão além das velhas fichas de conceitos programáticos ainda utilizados por alguns docentes, pois se acredita não ser possível transformar a realidade em conceitos e resumi-los em textos e manuais. Essa postura destrói qualquer responsabilidade humana, especialmente cidadã, que aposta em uma vida qualitativa, não obstante sua improbabilidade.

Os conteúdos de aula já prontos, estampados em manuais esquematizados, aniquilam os sentidos, marginalizam as sensações e criam distanciamentos entre a teoria debatida em sala de aula com a realidade existente por meio dos muros escolares. Percebe-se que o mundo do Direito se distancia, mais e mais, do mundo real e o despreza porque esse não é o local legítimo, nem racional, para se promover as desejáveis mudanças na dimensão humana.

É necessário ultrapassar a concepção de que o aluno possui em seu intelecto um espaço vazio, o qual precisa ser moldado pelo docente com conteúdos prontos necessários ao aprendizado específico de uma

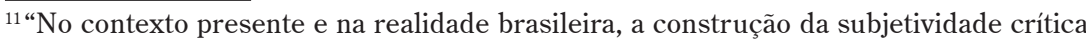
depende sobretudo de um fortalecimento da autonomia do indivíduo, plenamente tragado pelas exigências da sociedade de controle, da sociedade pós-moderna” (BITTAR, 2011, p. 44).
} 
disciplina, pois o que se espera é a constante ressignificação e desenvolvimento de novos conhecimentos diante das realidades vivenciadas pelos acadêmicos.

Cita-se como exemplo comparativo as aulas dos cursos jurídicos com as dos cursos voltados às engenharias. $\mathrm{O}$ segundo, frequentemente, cria espaços diferenciados de ensino, conta com laboratórios, instrumentos, experiências, análises e construções práticas. Os alunos são provocados e instigados a superarem-se e surpreenderem-se constantemente, pois analisam seus contextos, fazem visitas de campo e técnicas e transcendem os limites impostos pelas quatro paredes monocromáticas das salas de aula, para se inserir no contexto externo que lhes aguarda.

No Direito, contudo, o acadêmico continua na sala de aula, a qual, muitas vezes, se assemelha a alguma espécie de "redoma" que cria, em seu interior, uma atmosfera singular, diferente da existente no âmbito externo. Ali, o acadêmico se esforça, muitas vezes, em vão, para se manter atento ao que o Professor fala, estabelecendo (im)possíveis relações com o longínquo contexto do mundo real. Não existe linguagem sem que o signo estabeleça contato com o significante.

Diante desse cenário, é possível afirmar, por meio de Kosik (1985, p. 206), que o conhecimento acontece no indivíduo quando este se sente diretamente envolvido com as temáticas analisadas, momento em que tece novas interpretações e relações cognitivas, ou seja, "conhecemos o mundo, as coisas, os processos somente na medida em que os 'criamos', isto é, na medida em que os reproduzimos espiritual e intelectualmente”.

É necessário que o professor se levante de sua cadeira, "sacuda a poeira” e, juntamente com as instituições de ensino jurídico, escondidas sob o véu da mercantilização do ensino, assumam o compromisso educacional que lhes é inerente. Nenhuma educação é capaz de ser o tempo do amadurecimento e esclarecimento, próprio das utopias, quando seus atores optam por se "educarem” a partir da "ilusão do conhecimento". 
A comparação feita anteriormente entre as distintas áreas do conhecimento nos projeta para o seguinte questionamento: Os Cursos de Direito não possuem relação com a realidade social? Carecem de um ambiente para a realização de práticas educacionais ou interdisciplinares?

Vive-se em uma Sociedade sem conflitos, ética e justa, a qual justifica a apresentação dos conteúdos jurídicos pelos manuais, igualmente compostos por relatos de outrora? A realidade pode ser transformada em conceitos e resumida em textos? Ou, ainda, como indaga Freire (1996, p. 30): "Por que não estabelecer uma 'intimidade' entre os saberes curriculares fundamentais aos alunos e a experiência social que eles têm como indivíduos?"

A Sociedade produz constantemente demandas ao meio jurídico, as quais, na grande maioria das vezes, seguem inovando-se, criando situações inéditas, e quando o acadêmico desconhece essa dimensão se depara com um mundo muito mais complexo do apresentado em sala de aula. Para que essa condição não ocorra, é necessário, nas palavras de Vasconcellos (2002, p. 86), “[...] superar aquela ilusão de facilidade que o educando tem ao assistir passivamente à explicação do mestre, vindo a perceber a dificuldade só mais tarde, quando do confronto pessoal com o assunto”.

Streck (2009, p. 82) destaca que Hegel, em uma de suas aulas, foi interrompido por um de seus alunos, o qual lhe perguntou: "Mestre, tudo isto que o senhor está dizendo não tem absolutamente nada a ver com a realidade". Nesse momento, Hegel teria respondido: "Pior para a realidade $^{12 ”}$.

${ }^{12}$ Para Hegel: "O que é racional, isto é efetivo; e o que é efetivo, isto é racional". (HEGEL, 2010, p. 41, grifos da obra estudada). Sob esse ângulo, Inwood (1997, p. 108-109) detalha essa afirmação: “[...] Usualmente, contrastamos o que é real ou efetivo com idéias ou pensamentos. Podemos então jogar realidade e idéias umas contra outras, afirmando que uma coisa é meramente uma idéia e não real ou realizável, ou, alternativamente, que a realidade está confusa, uma vez que colide com as nossas idéias ou ideais. Hegel quer demolir essa oposição. Para tanto, argumenta que os pensamentos e, em especial, 'a idéia', não são pri- 
É lamentável observar como a Realidade e o Direito se distanciam no decorrer dos tempos. Triste é perceber que a primeira expressão precisa se moldar aos discursos de muitos Professores, os quais, ao aplicarem determinados "filtros", acabam por distorcê-la, ou seja, não a compreendem como é. O resultado dessa deformação educacional são as interpretações equivocadas, esquematizadas, facilitadoras para um Direito mais lógico sem que haja qualquer preocupação com as pessoas.

Acredita-se que essa atitude de que é possível "salvar" todos pelas prescrições jurídicas é incapaz de trazer o mundo no qual se vive para as doutrinas lidas e relidas no espaço acadêmico. Ao se compreender a realidade como é, torna-se possível aos estudantes reconhecerem o contexto em que vivem para, após, traçarem novas e possíveis soluções para as mazelas sociais. O mundo não é somente pura abstração lógica, nem uma "verdade" extraída simplesmente dos fatos, mas um ato de comunicação entre dois ou mais lugares de sentido que se complementam. Cabe ao ser humano, e mais especificamente ao estudante de Direito e/ou jurista, interpretar a complexidade desse diálogo como é.

A busca pela facilitação, tanto para se "ensinar" quanto para se “aprender”, além de não traduzir, de modo adequado, a Realidade e o Direito, cria no imaginário a ideia de que a atuação profissional do jurista também será facilitada, ou seja, quando se aprende por modelos prontos, busca-se os mesmos critérios para uma atuação prática. Se essa ocorrência se torna habitual, verifica-se que as profissões jurídicas não cumprem a sua função social, mas persistem em um verdadeiro desserviço à Sociedade.

mordialmente entidades subjetivas, mas estão imanentes na realidade [...]. [...] A doutrina de que o efetivo é racional não constitui simplesmente um produto do conservadorismo de Hegel [...]. Também representa uma linha estóica e spinozista em seu pensamento, a crença em que é melhor compreender e considerar as coisas do que agitá-las ou alterá-las, e em que a LIBERDADE consiste no entendimento da necessidade, na medida em que esse entendimento nos habilita a aceita o mundo como ele é, em vez de querer mudá-lo". 
Essas reflexões evidenciam que, quando o acadêmico "moldado" sobre conteúdos programáticos não ultrapassa os limites impostos pela praxe educacional após graduado, esse se sente incapaz de resolver por si as questões que se apresentam no seu cotidiano profissional, pois, como observa Rosa (2014, p. 10), “[...] um processo penal é algo que se compreende artesanalmente, no contexto em que acontece, sabendo-se, de antemão, que o modelo teórico é aplicado com muitas variáveis em cada unidade jurisdicional”.

"Pior para a realidade", destacava Hegel, uma vez que muitos acadêmicos vivenciam suas crises vocacionais ao preencherem as vagas dos cursos jurídicos buscando tão somente estabilidade profissional e financeira, e juntamente com as escolas jurídicas, recriam a realidade sob novas perspectivas, facilitadas, posto que, somente nesse formato, de certa forma compactado, muitos acadêmicos a querem conhecer.

Por que ler livros inteiros se é possível apenas se contentar com rápidas (e indolores) informações dos resumos? Esses trabalhos (com aparência de) acadêmicos corroboram unicamente com o ponto de vista do Professor que o ensina. Por que ir até as zonas de conflitos e fontes de direito prático se os acadêmicos podem “conhecê-los” por meio dos equipamentos como o projetor Datashow ou a internet? O mundo da vida se tornou indiferente para os cientistas, pois é possível atomizá-lo e dissecá-lo nas quatros paredes da sala de aula. Como é possível educar para os Direitos Humanos nesse cenário? Por que e para que enfrentar as adversidades e os desafios da realidade?

Talvez grande parte das escolas jurídicas prefira não responder a essas indagações, pois encará-las não faz bem para a sua intocável tranquilidade intelectual e espiritual. Sob igual critério, nada deve afetar o intenso fluxo monetário que se origina de algumas academias jurídicas. Essas se promovem a partir de índices de aprovação de seus acadêmicos 
expressos pelos exames da Ordem dos Advogados do Brasil - OAB-, mas não tornam público os resultados de avaliação do Ministério da Educação e Cultura - MEC.

Os números excessivos de alunos em salas de aula, a má qualidade de seus docentes, a ausência de bibliotecas que não se fixem apenas no conhecimento jurídico, mas dialoguem nesse mosaico dos saberes humanos, entre outros fatores, tornam os cursos jurídicos tecnicistas, amorais, desumanos e dissociados da realidade social. Proteger o que e para quem? Eis o desafio perene de uma crítica reflexiva que nasce a partir de uma educação para o Direito, especialmente os Direito Humanos. ${ }^{13}$

"Pior para a realidade", insiste-se, pois, talvez, essa tenha de resolver sozinha os seus problemas. Quando conseguir, os acadêmicos dos cursos de Direito sairão de suas salas de aula, vestirão seus ternos blindados, suas luvas e botas de galocha e, com auxílio de uma lupa, analisarão fragmentos de um conflito que existiu em uma época inexistente.

\subsection{Luís Alberto Warat e a erudição vazia da doutrina}

Na busca por uma Sociedade mais humana, se faz necessário repensar o processo de ensino e firmar novos caminhos para promovê-lo. Diante desse cenário, surgiram consideráveis contribuições de Warat, o qual rea-

\footnotetext{
13 "Chaplin, nos seus diversos personagens, retrata essa condição de sobrevivência imposta pelo início do século XX na figura do Monsieur Verdoux. Para aqueles que não conhecem esse filme, o personagem principal tem uma dupla vida: uma na cidade, passando-se por cidadão nobre que casa com várias senhoras ricas daquela Sociedade e outra no campo no qual é um farmacêutico local que luta para garantir a sobrevivência de sua filha e sua esposa paralítica. Na vida da metrópole, contudo, ocorre exatamente o contrário das personae vividas por Chaplin, ou seja, trata-se de um assassino que, diante da crise que assola o início do século XX, mata para conseguir sua subsistência familiar. Não seria esse o movimento (de violência) criado pela Modernidade contra o desenvolvimento das pessoas? Acomodação, Certeza e Sobrevivência (física) x Incerteza, Formação e Cultura? Sem essa preocupação de ordem dialógica, o Direito somente se reproduz por meio de seus dogmas, não aceitando qualquer indagação a esses meios" (AQUINO, 2014, p. 59).
} 
lizou releituras de métodos de ensino aplicados e, por meio de ideias mais radicais, marcou significativamente o universo jurídico. Warat acreditava na “doutrina que não doutrina”. Protagonizou, nessa linha de pensamento, novas maneiras de compartilhar conhecimentos, ao reformular premissas antigas conforme um Direito crítico, reflexivo e profundamente humano.

Parte-se do pressuposto de que a afetividade ${ }^{14}$ é um elemento fundamental ao processo de ensino por meio da qual se estabelece um ambiente propício à participação do aluno. A partir do processo educacional consolidado por Warat, percebe-se que os envolvidos se sentem instigados a desenvolver um novo mundo e necessitam expressar suas capacidades mais profundas. O Professor, para Rocha (2012), deve permitir, ampliar, aperfeiçoar e contribuir para que a criatividade saia da abstração e seja iluminada pela realidade. Pensa-se, possivelmente, em um "Iluminismo Sensivel”. ${ }^{15}$

A didática de Warat projeta as pessoas para o centro do processo didático, ensina com paixão e criatividade, bem como defende que o ordenamento jurídico não é um sistema autônomo, pleno e lógico. Nesse argumento, o pensamento jurídico tradicional necessita ser repensado e

14 “[...] O afeto, o emocional, o afetual, coisas que são da ordem da paixão, não estão mais separados em um domínio a parte, bem confinados na esfera da vida privada; não são mais unicamente explicáveis a partir de categorias psicológicas, mas vão tornar-se alavancas metodológicas que podem servir à reflexão epistemológica, e são plenamente operatórias para explicar os múltiplos fenômenos sociais que, sem isso, permaneceriam totalmente incompreensíveis" (MAFFESOLI, 2008, p. 53).

${ }^{15}$ Fenômeno histórico no qual sugere, continuamente e de modo crítico, a (des)constituição, a indagação e a criação dos saberes que erigem as relações entre as pessoas todos os dias - sejam sociais, profissionais, institucionais. Não se estabelece um período de tempo para sinalizar o início e fim dessa expressão, pois sua função não é determinada, de modo específico, para um momento histórico, mas, no seu decorrer, rememorar o que significa ser humano em seus múltiplos diálogos. Integra-se o lúdico e a coerência lógica, admite-se a pluralidade de fenômenos capazes de comporem os matizes do domínio científico, social, tecnológico, político, entre outros. Transita-se no ir e vir do relacionar-se e comunicar-se, nas diferentes redes de interação humana, para encontrar o que se torna fundamental ao conviver diário. 
recriado sobre as mutáveis perspectivas sociais. No destaque de Warat (2004, p. 237), esse modo de pensar é estruturado sobre os ensinamentos de Hans Kelsen e aduz-se que "A teoria Kelseniana, através do postulado da pureza metódica, separa radicalmente o conhecimento científico do Direito do seu conhecimento operativo”.

O citado autor (1985, p. 133) defendia uma visão surrealista como expressão artístico-literária, objetivando a exteriorização das vivências dos acadêmicos. Esta atitude pedagógica tinha em vista a liberdade das verdades e certezas em prol do aprendizado, evitando, assim, a “castração” do pensar. "Ao carnavalizar a aula, ter-se-á a esmagadora sensação de estar presente na vida. Sairemos dela leves. Teremos espantado os lugares pré-montados e negado a palavra autoritária. A didática carnavalizada é uma excelente possibilidade para destruir a relação mestre-discípulo”.

A doutrina deve ser livre, pode e tem de se conectar com as diversas dimensões - artificiais ou naturais - para se atualizar constantemente. A educação para os Direitos Humanos necessita fundamentar-se sob essas premissas a fim de insistir em uma doutrina que não apenas doutrine, mas compreenda a ambivalência e ambiguidade de ser profundamente humano em seu perene diálogo intra e interpessoal. Eis o desafio de nossa perene humanização pelas vidas da educação.

\section{HUMANIZAÇÃO DOS DIREITOS HUMANOS}

Não existe conhecimento crítico quando o formar aprisiona, reprime, adormece os desejos e extingue a criatividade. Nesse momento, percebe-se a deformação do pensar. Para Bittar (2011, p. 41), formação e deformação estariam lado a lado, porque “[...] essas forças contraditórias são capazes de produzir horrores históricos, morais, políticos, ideológicos, 
o que motiva por si só que se repense que sentido possuem as práticas científicas, as pedagogias educacionais e o que engendram a partir das mesmas".

Como humanizar? Como instalar no íntimo do ser a semente do amor ao próximo, do desejo puro de justiça, da solidariedade e civilidade? Esses paradigmas são cada vez mais difíceis de conquistar, pois, diante da educação aniquiladora, recebida em muitas academias jurídicas, o indivíduo se percebe diante da realidade que não é a sala de aula e carece de reflexões, posicionamentos críticos embasados, ou seja, se deixa levar pelo pensar e agir das massas condicionadas, muitas vezes, pelos meios de comunicação sensacionalistas.

Aquele acadêmico que, nos primeiros semestres da Graduação em Direito, adotava uma postura questionadora e se deslumbrava pelo universo jurídico, passa a vestir-se de um comportamento mecanizado e programático. Esse acadêmico torna-se um replicador engessado dos conteúdos oriundos das Faculdades de Direito e adota um perfil passivo diante dos fatos. O mundo e sua miséria não causam mais nenhum remorso capaz de sensibilizar a práxis dos Direitos Humanos. Por esse motivo, as palavras de Coccia (2010, p. 9) precisam ser meditadas:

Vivemos porque podemos ver, ouvir, sentir, saborear o mundo que nos circunda. E somente graças ao sensível chegamos a pensar: sem as imagens que nossos sentidos são capazes de captar, nossos conceitos, tal qual já se escreveu, não passariam de regras vazias, operações conduzidas sobre o nada. A influência da sensação e do sensível sobre nossa vida é enorme, embora permaneça praticamente inexplorada. Enfeitiçada pelas faculdades superiores, a filosofia raramente mediu o peso da sensibilidade sobre a existência humana. Esforçando-se por provar e fundar a racionalidade do homem, procurando separá-lo a qualquer custo do resto dos animais, ela frequientemente esqueceu que todo homem vive no meio da experiência sensível e que pode sobreviver apenas graças às sensações. 
Esse cenário está em extinção, fadado ao esquecimento. A barbárie $^{16}$ está em todos os lugares; nas relações interpessoais, nas tarefas diárias, pode ser percebida nos diálogos dos casais, roda de amigos, relação entre pais e filhos. Os indivíduos desrespeitam o próximo e procuram afastar-se dos menos favorecidos, alienando-se do mundo real, vivendo suas vidas como se todos ao seu redor vivessem bem e felizes.

A felicidade, como bem de consumo, está exposta em uma prateleira de supermercado, disponível apenas para os que possuírem condições de comprá-la. Os que não a tem não são dignos de viver em Sociedade. Os seres humanos são afastados para as periferias, não apenas pela dimensão geográfica, mas, principalmente, pelas relações sociais. Como romper com esse ciclo de exclusão social? Como fazer valer os direitos e deveres dos cidadãos em uma Sociedade que deve ser cívica e democrática? Pela educação capaz de sensibilizar ${ }^{17}$ e emancipar!

Os Direitos Humanos, descritos como valores indispensáveis ao convívio, devem ser promovidos não somente nas faculdades de Direito, mas nas demais Graduações, nas escolas de Educação Infantil, nas comunidades, nas famílias, entre outros meios. As pessoas precisam conhecer seus direitos, mas, principalmente, os seus deveres. O reconhecimento de suas importâncias como vetores de integração e organização humana, entretanto, somente decorrem de nossas responsabilidades comuns. A aplicação da lei é tão somente uma decorrência dessa experiência com o Outro no mundo da vida.

\footnotetext{
16 "A barbárie [...] é consequência de imposições de um excesso de condições racionais que levam à implementação ou radicalização de atitudes e modos de organização social-totalitárias. O totalitarismo sempre deve ser visto como um excesso de racionalismo" (WARAT, 2010, p. 106)

${ }^{17}$ Bittar (2011, p. 69, grifos da obra estudada), acerca dessa afirmação, enfatiza: “[...] a educação em direitos humanos deve preparar para a tolerância entre diferentes e para a solidariedade entre desiguais, realizando a necessidade de constituição de sujeitos preparados para a cidadania e para a parceria social. A educação $\mathrm{em}$ direitos humanos e para os direitos procuram estimular todas as formas pelas quais se possa chegar a conceber o resgate do sujeito, e a sensibilidade não é um aspecto irrelevante dessa dinâmica”.
} 
Vive-se em uma Sociedade na qual o crime tornou-se um produto e quanto mais bárbaro, melhor! Os programas "crime-show" conquistam cada vez mais telespectadores, os quais acompanham fielmente a apresentação sensacionalista daqueles que enriquecem e se promovem ao mostrar, de forma atroz, as violências e mazelas sociais. Embrutece-se, mais e mais, o ser humano, seja pelas atrocidades do dia a dia, seja pela reivindicação de eliminação do Outro como resposta rápida e indolor aos (complexos) conflitos humanos.

Não se espera que os crimes permaneçam impunes e as pessoas se alienem diante da realidade, especialmente a social, mas acredita-se que a violência, quando exaltada e transformada em protagonista de um circo midiático, resultará em fatores demasiadamente negativos, como em um primeiro momento, se observa na promoção de mais violência, na exaltação do senso primitivo de justiça e da busca pela sobrevivência, quando o próximo é percebido e sentido como um adversário.

Em segundo lugar, o fomento da cultura do medo aprisiona os indivíduos em suas casas, as quais são cercadas por muros altos e sistemas de segurança. Novamente: a anestesia contra nosso vínculo antropológico comum é o melhor remédio para se manter as redes de Socialidade. ${ }^{18}$ Eis o paradoxo que, aos poucos, se transforma em aporia.

Como pensar em Direitos Humanos quando parte da Sociedade se afasta do mundo real, da vida, e se aprisiona em seus núcleos, seguros e fartos? Como transgredir as fronteiras do "Eu" na direção dialogal do "Tu”? Vive-se, na verdade, o "salvem-se quem puder!" Os que podem, o fazem alienando-se do restante, mas os que não podem, seguem "lutando" pelo pouco de dignidade que lhes resta.

\footnotetext{
18 "Socialidade denota a identificação existente no aparente banal, ao contrário das características de identidade, pois, enquanto aquela se encontra na múltipla efervescência do cotidiano, na vivência plural, essa significa a essência individualista” (AQUINO, 2011, p. 47).
} 
Não é possível vivenciar uma cultura centrada no convívio plural e na aceitação da diversidade, no respeito à Dignidade Humana ${ }^{19}$ e na preocupação com a Justiça Social20 quando os seres humanos não se conectam, não falam, não reconhecem as adversidades e fragilidades do mundo em que vivem.

O que falta? Educação! ${ }^{11}$ Enquanto se viverem uma Sociedade que segrega a educação de qualidade, jamais se conquistará equilíbrio social. É inadmissível faltarem escolas, cursos de Graduação, Mestrados e Doutorados para os que desejarem seguir por esses caminhos. Talvez, por

19 “A dignitas é um atributo que se confere ao indivíduo desde fora e desde dentro. A dignidade tem a ver com o que se confere ao outro (experiência desde fora), bem como com o que se confere a si mesmo (experiência desde dentro). A primeira tem a ver com o que se faz, o que se confere, o que se oferta [...] para que a pessoa seja dignificada. A segunda tem a ver com o que se percebe como sendo a dignidade pessoal, com uma certa auto-aceitação ou valorização-de-si, com um desejo de expansão de si, para que as potencialidades de sua personalidade despontem, floresçam, emergindo em direção à superfície. Mas, independentemente do conceito de dignidade própria que cada um possua (dignidade desde dentro), todo indivíduo é, germinalmente, dela merecedor, bem como agente qualificado para demandá-lo do Estado e do outro (dignidade desde fora), pelo simples fato de ser pessoa, independente de condicionamentos sociais, políticos, étnicos, raciais, etc. [...] Só há dignidade, portanto, quando a própria condição humana é entendida, compreendida e respeitada, em suas diversas dimensões, o que impõe, necessariamente, a expansão da consciência ética como prática diuturna de respeito à pessoa humana” (BITTAR, 2009, p. 301-302).

20 “[...] quando se solicita JUSTIÇA SOCIAL, não se pode realizar o apelo ingênua ou maliciosamente - como se o seu destinatário único fosse o Estado, ou um outro, como o Governo. O verdadeiro destinatário dos apelos à JUSTIÇA SOCIAL é o seu Agente: - o todo social, ou seja, a Sociedade. A JUSTIÇA SOCIAL somente apresentará condições de realização eficiente, eficaz e efetiva se a Sociedade, no seu conjunto, estiver disposta ao preciso e precioso mister de contribuir para que cada pessoa receba o que lhe é devido pela sua condição humana. E, da parte do Estado, caso ele exerça uma efetiva, contínua e legítima Função Social. Neste contexto, destaco três pontos estratégicos: $1^{\circ}$ - a noção de JUSTIÇA SOCIAL não pode ser presa a esquemas fixados $a$ priori e com rigidez indiscutível; $2^{0}-\mathrm{a}$ conduta do Estado não pode ser paternalista para com os necessitados e protetora ou conivente para com os privilegiados; $3^{\circ}$ - a responsabilidade pela consecução da JUSTIÇA SOCIAL na sua condição de destinação da FUNÇÃO SOCIAL, deve ser partilhada por todos os componentes da Sociedade” (PASOLD, 2013, p. 55).

21 "Talvez o caminho para se recuperar o Direito e seu ensino como forma de libertação, colocando-o a serviço de toda sociedade, da democracia, da justiça social - reinventando o desejo e o sonho e aceitando as diferenças -, esteja na construção de discursos marginais - avessos ao padrão de normalidade dominante - que consigam, a partir da proposição de 
esse motivo, seja necessário refletir que a educação não é objeto, não é mercadoria, não é um "guia” de salvação para a humanidade. Ao contrário, é o pressuposto de esclarecimento sobre a necessidade de um olhar intrapessoal para se enxergar no Outro - olhar interpessoal - a necessidade de nossa perene humanização, de nossas virtudes e vícios enquanto todos pertencerem ao gênero humano ${ }^{22}$.

Espera-se que a composição poética dos Direitos Humanos, estruturada sobre uma construção sócio-histórica-cultural, caracterizada pela barbárie de todos os dias, se reestruture, se reinvente e, como um digno soneto e encante, surpreenda o leitor ou leitora acerca de se desenvolver, por meio da educação, uma sensibilidade aguçada o suficiente para se identificar as mazelas que dificultam ou impedem nossas relações diárias, bem como a chance de todos terem uma vida qualitativa.

\section{EDUCAÇÃO, DIREITOS HUMANOS E SENSIBILIDADE JURÍDICA: Por Uma Democracia Utópica e Barroca}

A importância de uma educação para os Direitos Humanos não é algo que insista na sua abstração, na sua universalidade, na sua atemporalidade, ${ }^{23}$ mas na pulsão cotidiana das adversidades vivenciadas

novos universos simbólicos, criar utopias e caminhar no sentido de efetivá-las. Sonhar com o novo e lutar pela sua realização já é o primeiro passo para a sua concretização. Marginalidade e utopia talvez sejam o início de um novo caminho...” (RODRIGUES, 2000, p. 29).

${ }^{22}$ Essa atitude, descrita como pensamento crítico, é, “[...] genuinamente, sensível à dimensão da alteridade, porque engajado com a dimensão da intersubjetividade e disposto a pensar processos de socialização que possam guindar a humanidade em direção a processos de maior acúmulo de desenvolvimento moral” (BITTAR, 2011, p. 74).

23 "Os direitos humanos, desde a sua origem e como são concebidos modernamente pela cultura ocidental universalizada, são caracterizados por uma ambiguidade. A esperança em alcançarmos um padrão mínimo jurídico e ético para garantir igualitariamente a dignidade humana, convive, contraditoriamente, com a violação de tais garantias, com a consequente 
por todos. Quando se observa que alguém, em algum lugar, passa fome, é desprovido de direitos e cidadania, não tem amparo por serviços públicos indispensáveis a sua manutenção, vive, diariamente, a partir do medo causado pelos conflitos armados, não é reconhecido, em nenhum território, como humano, por suas diferenças culturais, não é possível afirmar que os Direitos Humanos cumpram a sua função social.

Todos esses cenários precisam, de um jeito ou outro, resgatar a importância das relações humanas que constituem as possibilidades de uma vida democrática no mundo. No momento em que a educação, auxiliada pelo Ensino,${ }^{24}$ não se importa com a nossa "cegueira moral”, com as nossas irresponsabilidades, é improvável que os significados originários da descoberta acerca do Outro expressem a transformação utópica dos Direitos Humanos como conquista histórica de reconhecimento do nosso vínculo antropológico comum. Nessa linha de pensamento, Warat (2010, p. 118) é enfático: “[...] Já dissemos que sem alteridade toda fala dos Direitos humanos termina em piada ou drama”.

produção de genocídios, imperialismo e ocultamentos. A universalidade desses direitos despreza a práxis da relação humana nos diferentes contextos culturais no globo. O silêncio contra a dignidade parece uníssono” (GRUBBA; AQUINO, 2015, p. 1964).

24 "O ensino jurídico mercadurizado, tornado objeto de fetiche, ou como forma de ascensão social rápida, se converteu em um ensino forjado a partir das exigências da heteronomia de mercado. Por isso, sua função preparatória (formativa) se minimiza em uma função instrutória (deformativa). Faculdades de Direito se tornam, não raro, fábricas de adestramento (que se faz com ratos de laboratório por condicionamento) aos imperativos de mercado, às exigências imediatistas. [...] Se é realidade hoje que Faculdades de Direito não formam juristas, propriamente ditos, pode-se ir mais longe para se dizer que Faculdades de Direito sequer chegam a formar operadores de Direito, mas produzem em escala quase fabril quantidades enormes de operários do sistema” (BITTAR, 2006, p. 28-29). 
Os Direitos Humanos ${ }^{25}$ se reinventam, diariamente, por uma educação na qual esclareça a Alteridade como experiência de infinição do infinito, ${ }^{26}$ nas palavras de Lévinas, bem como estimule a sensibilidade pela fragilidade, adversidade e virtudes dessa obra de arte chamada cotidiano. $\mathrm{O}$ ato de educar para a compreensão e práxis dos referidos direitos é, genuinamente, uma aposta nas utopias carregadas de esperança, conforme já sinalizava Melo (1994, p. 19).

As diferentes e plurais utopias que habitam esse mundo não podem ser assemelhadas à Quimera, ${ }^{27}$ uma besta que nunca deixou a dimensão imaginária, abstrata. Ao contrário, a função transformadora das utopias é aquilo que possibilita o agir pela indignação ${ }^{28}$ não violenta para transfor-

25 "No âmbito dos direitos humanos, dizer que os direitos são inerentes e que decorrem de uma suposta natureza humana significa dizer que existe um fundamento metafísico na natureza do homem, mas não significa que parece haver uma defesa, por parte da Organização das Nações Unidas, do direito natural. Isso porque, diferentemente da ideia de um direito natural imutável, não existe um rol definitivo dos direitos humanos. Os direitos humanos, no plano jurídico, não se confundem com os direitos naturais, visto que são aqueles positivados e mutáveis no tempo”. (GRUBBA, 2016, p. 138)

${ }^{26} \mathrm{~A}$ ideia do infinito, conforme Lévinas, “[...] não é uma noção que uma subjectividade forje casualmente para reflectir uma entidade que não encontra fora de si nada que a limite, que ultrapassa todo limite e, por isso, infinita. A produção da entidade infinita não pode separar-se da idéia do infinito, porque é precisamente na desproporção entre a idéia do infinito de que ela é idéia que se produz a ultrapassagem dos limites. A idéia do infinito é o modo de ser - a infinição do infinito. $O$ infinito não existe antes para se revelar depois. A sua infinição produz-se como revelação, como uma colocação em mim da sua idéia. Produz-se no facto inverossímil em que um ser separado fixado na sua identidade, o Mesmo, o Eu contém, no entanto, em si - o que não pode nem conter, nem receber apenas por força de sua identidade. A subjectividade realiza essas exigências impossíveis; o facto surpreendente de conter mais do que é possível conter" (2000, p. 14).

27 “[...] A Quimera, figura de alhures, é certamente utopista pelo fato de que através dela se percebe o processo de destruição/reconstrução que leva de um mundo real a um outro mundo real (suposto): o ser fantástico mostra que o real atual é ordem relativa que uma desordem poderia transformar em outra ordem. Mas Utopia não é uma Quimera: ela é (imaginariamente) o tempo do processo, ou seja, uma nova realidade cuja essência aparece diretamente na existência” (LACROIX, 1996, p. 65).

28 "Eu desejo a todos, a cada um de vocês, que tenham seu motivo de indignação. Isto é precioso. Quando alguma coisa nos indigna, como fiquei indignado com o nazismo, nos transformamos em militantes; fortes e engajados, nos unimos à corrente da história, e a grande corrente da história prossegue graças a cada um de nós. Essa corrente vai em 
mar o momento presente insuportável ao desejável, àquilo que pode vir a ser. Por esse motivo, Melo (1994, p. 55) sempre destacou: "As utopias, unindo inteligência e emoção, razão e sentimento, funcionam como projetos sociais de transformação e mudança; melhor dizendo, como projeção da Sociedade que deve ser”.

Utopia, em nenhum movimento, significa ausência de movimento, de sensações, de práxis, mas reivindica, constantemente, a indagação: $\mathrm{O}$ que é necessário para constituir esse "lugar inexistente" e torná-lo real? $\mathrm{Na}$ medida em que se observa a intensidade do fluxo desse rio heraclitano, nas palavras de Husserl (2004, p. 59), Educação e o Mundo da Vida não são dimensões separadas, mas unidas. O constante ir e vir de um diálogo não se inicia, nem termina, nas fronteiras do "Eu”, porém se desenvolve no circuito "Eu-Tu-Mundo-Nós".

Esse é o nó górdio que a educação para os Direitos Humanos precisa esclarecer como pressuposto utópico fundamental aos ambientes democráticos: somos um em todos e todos em um. A totalidade ${ }^{29}$ de sentidos, buscada historicamente para se cumprir, globalmente, os objetivos dos referidos direitos, surge a partir de um quebra-cabeça que ocorre, todos os dias, em diferentes lugares e culturas, pelas relações humanas cotidianas. Se a educação não oportunizar essa sensibilidade para a impor-

direção de mais justiça, de mais liberdade, mas não da liberdade descontrolada da raposa no galinheiro. Esses direitos, cujo programa a Declaração Universal redigiu em 1948, são universais. Se você encontrar alguém que não é beneficiado por eles, compadeça-se, ajude-o a conquistá-los” (HESSEL, 2011, p. 16).

29 “A totalidade, no sentido em que a concebemos, não é uma visão da realidade imediata e eternamente válida, somente atribuível a olhos divinos. Não se trata de um horizonte estável e autodelimitado. Pelo contrário, uma visão total implica tanto a assimilação quanto a transcendência das limitações dos pontos-de-vista particulares. Representa o contínuo processo de expansão do conhecimento, possuindo como objetivo não atingir uma conclusão válida supratemporalmente, mas a extensão mais ampla possível de nosso horizonte de visão" (MANNHEIM, 1982, p. 132). 
tância democrática das diferenças como vetor de integração, qualquer projeto que determine a necessidade desse estar-junto-com-o-Outro-no-mundo $o^{30}$ será, apenas, uma mentira existencial compartilhada por todos.

O papel central de uma educação para os Direitos Humanos, na ênfase de Cunha (2007, p. 170), labora, de modo persistente, pela viabilidade real dos mundos imaginários. A vivência constante das adversidades, da crueldade, da violência, da instabilidade de direitos e instituições, estimula imaginação e imaginários acerca de uma vida qualitativa, tolerante ${ }^{31}$, pacífica, harmoniosa. Há uma obviedade que precisa ser o mantra dos citados direitos, conforme adverte Maffesoli (2014, p. 250): “[...] A sintonia com o mundo e com os outros é o denominador comum em todas as experiências vividas”.

30 “[...] é preciso que haja o Outro para que cada um exista. Truísmo que a biologia, a genética e o social analisam à vontade, e que o senso comum vive, empiricamente, no dia a dia, mas que nossas evidências ideológicas, as da modernidade, se dedicam constantemente a negar. Curiosa persistência de uma ideologia individualista da qual a razão certa e o bom senso reunidos reconhecem a vacuidade! Ser é estar-com, isto é, ajustar-se às leis de harmonia de ordem universal. Não é assim que se pode compreender Anaximandro quando ele fala de diké? Não estreitamento sobre o valor moral e jurídico (o que equivale à mesma coisa) de 'justiça', mas, ao contrário, pela ideia de 'adjunção', isto é, coexistir com a totalidade do mundo, em sua naturalidade ou em sua socialidade” (MAFFESOLI, 2014, p. 87).

31 “A Tolerância torna visíveis os limites de nossas certezas e acolhe essa diferença que está além das fronteiras perceptivas do 'Eu'. Essa postura é inexistente por aquele que pratica o seu contrário - a intolerância27 -, porque a ausência desse terreno fértil, de se acolher a diferença humana alheia, impõe um modus vivendi sem liberdades, sem proximidade. É a negação da condição (e natureza) humana. Tolerar exige, sob esse argumento, o Perdão, pois, como salienta Voltaire, é o fundamento que se manifesta a partir do reconhecimento no qual se comunga nossas fragilidades, nossos erros. Ao se admitir essa condição, intrassubjetiva e intersubjetiva, resta a indagação: Por que não perdoar? Percebe-se nessa ação uma aposta de regeneração, ao contrário da intolerância, que dissemina atitudes destrutivas. O improvável se corporifica e resiste, manifesta-se contra a violência, a crueldade, as imposições culturais arbitrárias e regenera as relações humanas tornando-as mais amistosas e sadias. Esse é o vínculo de Responsabilidade na qual se constitui historicamente por meio do 'estar junto', e se torna o sedimento que amplia o exercício habitual da Tolerância" (ZAMBAM; AQUINO, 2015, p. 374). 
Não se trata tão somente de vivificar, de rememorar o que é o Ser humano e suas responsabilidades diante do Outro, as quais, hoje, procuram-se sempre anestesiar em razão da insistente e multiterritorial dor moral $^{32}$. Trata-se, no âmbito do Direito, de se iniciar o estímulo para uma Sensibilidade Jurídica para que o jurista ${ }^{33}$ não se torne silente diante das atrocidades e desigualdades que se tornam critérios normais de Socialidade. Essa é a função crítica na elaboração do conhecimento acerca dos Direitos Humanos.

O theatrum mundi, encenado no cotidiano, ilumina esse des-velo de saberes dialogais entre os seres humanos e o mundo como "ser próprio". Essa Razão Sensível, ${ }^{34}$ matriz de uma Sensibilidade Jurídica, se manifesta,

32 "Com a negligência moral crescendo em alcance e intensidade, a demanda por analgésicos aumenta, e o consumo de tranquilizantes morais se transforma em vício. Portanto, a insensibilidade moral induzida e maquinada tende a se transformar numa compulsão ou numa 'segunda natureza', uma condição permanente e quase universal - com a dor moral extirpada em consequência de seu papel salutar como instrumento de advertência, alarme e ativação. Com a dor moral sufocada antes de se tornar insuportável e preocupante, a rede de vínculos humanos composta de fios morais se torna cada vez mais débil e frágil, vindo a se esgarçar. Com cidadãos treinados a buscar a salvação de seus contratempos e a solução de seus problemas nos mercados de consumo, a política pode (ou é estimulada, pressionada e, em última instância, coagida a) interpelar seus súditos como consumidores, em primeiro lugar, e só muito depois como cidadãos; e a redefinir o ardor consumista como virtude cívica, e a atividade de consumo como a realização da principal tarefa de um cidadão" (BAUMAN; DONSKIS, 2014, p. 24).

${ }^{33}$ Nas palavras de Warat (2010, p. 50): “[...] os juristas se mostram com uma inquietante incapacidade de escutar os sentimentos das pessoas. Esses sentimentos se encontram encobertos por camadas de representações ideológicas que são escutadas, porém, de um modo mais estridente que impossibilita qualquer outra escuta. Os juristas terminam só escutando, de modo autorreferencial, as vozes e crenças de sua ideologia funcional ou institucional; as escutam e ficam fascinados por elas a ponto de gerar um processo em que terminam devorando-se a si mesmos por conta de suas ideologias”.

34 “[...] A razão sensível desenvolve-se para suceder a razão instrumental, tão a gosto do racionalismo da modernidade. [...], a razão sensível não possui um conceito fechado de seu significado. Está em jogo, no pulsar da vida, a alma humana, o traço que a distingue encontra-se no afeto, na inocência, na intuição, na poesia, no amor. [...] A flor que nasce nas estepes geladas do leste europeu guarda idêntica natureza genética da flor que brota nas savanas da África. Do mesmo modo, a natureza humana. O ser humano de cor escura possui natureza genética igual ao da região nórdica, ou hindu, ou americana. $\mathrm{O}$ fio condutor do sentimento é comum a toda espécie da natureza humana” (SILVA, 2009, p. 231). 
antes, como intuição ${ }^{35}$ e, após, ação. Trata-se de uma atitude raciovitalista ${ }^{36}$ que não abandona a Razão, mas a obsessão eficientista do racionalismo. Nenhuma educação para os Direitos Humanos fomenta o reconhecimento do Outro pelo en-cobrimento de sua complexidade e diferença, tampouco pelas tentativas de colonizá-lo, mas, antes, por aquilo que o choque das experiências oportuniza como clareza na perspectiva da con-vivência.

É necessário, nesse momento, identificar a Sensibilidade Jurídica como experiência de proximidade, Cuidado ${ }^{37}$ e Alteridade, cujos efeitos repercutem na dimensão do Direito, especialmente sob o seu ângulo normativo. A Sensibilidade Jurídica não se confunde com a Consciência Jurídica ${ }^{38}$. A primeira expressão antecede a segunda e indica quais experiências denotam a nossa capacidade de integração e metamorfose, para, depois, por meio da Consciência Jurídica, se indicar os limites, as avaliações, as possibilidades de se formular normas jurídicas capazes de preservar a organização social.

35 “[...] Não entendo a intuição como simples qualidade psicológica. É até possível que ela seja tudo menos pessoal. [...] Nesse sentido, ela constitui um substrato arcaico, um 'resíduo', um arquétipo que assegura, a longo prazo, a perduração de todo um conjunto social” (MAFFESOLI, 2008, p. 131).

36 “[...] É essa sensibilidade que pode permitir compreender o que vem a ser uma racionalidade aberta. Ao contrário do racionalismo estreito e algo estático, ela apela para uma espécie de entusiasmo, no sentido mais forte do termo, que põe em ação uma força instintiva da qual se pode ressaltar o caráter 'demoníaco'. Assim se exprime a sinergia da razão e do sensível” (MAFFESOLI, 2008, p. 53).

${ }^{37}$ Para Boff, essa condição se traduz como “[...] desvelo, solicitude, diligência, zelo, atenção, bom trato. [...] O cuidado somente surge quando a existência de alguém tem importância para mim” (BOFF, 2008, p. 91).

38 "Aspecto da Consciência Coletiva [...] que se apresenta como produto cultural de um amplo processo de experiências sociais e de influência de discursos éticos, religiosos, etc., assimilados e compartilhados. Manifesta-se através de representações jurídicas e de juízos de valor" (MELO, 2000, p. 22). Grifos originais da obra em estudo. 
A Sensibilidade Jurídica, retratada como razão sensível intuitiva ${ }^{39}$, não elimina nenhuma experiência por mais trágica que possa se manifestar. É nesse diálogo entre diferentes lugares, seres e momentos o qual se consegue promover, talvez, condições de esclarecimento para o momento presente.

Por esse motivo, compreende-se essa categoria - Sensibilidade Jurídica - no seguinte conceito operacional: é o ato de sentir algo junto a pluralidade de seres, lugares, momentos e linguagens que constituem a vitalidade e dinâmica da Terra, cujas diferentes maneiras de cumplicidade denotam condições de pertença e participação, as quais precisam ser expressas pelo Direito [continental ou global] para assegurar condições - históricas ou normativas - sobre a importância do des-velo da Alteridade no vínculo comunicacional entre humanos e não humanos.

Se a Sensibilidade Jurídica representa esse novo saber na Pós-Modernidade, reconhece-se, desde logo, que o seu locus não reside tão somente na dimensão legal, jurisprudencial ou doutrinária do Direito. Essa categoria se expressa como saber ecosófico a fim de oportunizar condições de se estar-junto-com-o-mundo e compreendê-lo sob seus diferentes matizes, além daqueles (im)postos pelos domínios do "Eu”.

Essa comunhão de experiências - desde aquelas consideradas microscópicas (importância dos seres unicelulares como matriz de sustentabilidade a todos os seres, pequenos gestos que ocorrem no dia adia)

\footnotetext{
${ }^{39}$ Para que essa tarefa ocorra, é necessário “[...] alguém que saiba reconhecer que, no devir cíclico das histórias humanas, o instituinte, aquilo que periodicamente (re)nasce, nunca está em perfeita adequação com o instituído, com as instituições, sejam elas quais forem, que sempre serão algo de mortíferas. De certa forma, a intuição como forma de antecipação. Frisei bem que se trata de uma sensibilidade intelectual. Sensibilidade de modo algum exclusiva, mas que tem, também ela, seu lugar no quadro dos meios que a sociedade se dá para compreender a si própria. Sensibilidade que se inscreve, de maneira geral, naquela filosofia do 'sim' da qual Nietzsche foi o promotor. Filosofia vitalista e trágica que, bem ou mal, aceita aquilo que é enquanto tal, e reconhece a beleza do dado mundano" (MAFFESOLI, 2008, p. 131). Grifos originais da obra estudada.
} 
ou macroscópicas (o Planeta como única p[m]átria, perspectivas de vida estéticas, afetuais, políticas, sociais, culturais, econômicas, tecnológicas, ambientais, entre outras) estabelecem condições racionais que se manifestam por si e demonstram a necessidade de preservar a sua dimensão ontológica pelos instrumentos criados por um Direito, seja local, estadual, nacional, continental ou global.

Quando a educação para os Direitos Humanos fomenta a Sensibilidade Jurídica como fundamento à Consciência Jurídica, observa-se a epifania de que o convívio é uma arte, em que o reconhecimento dos sujeitos como sujeitos viabiliza a participação de todos como resistência contra todas as barbáries cujas atitudes extirpam, negam, segregam o sentimento de pertença na humanidade comum. A educação que privilegia as "andarilhagens históricas" observa a beleza como vetor de integração, de Socialidade, de proximidade, de zelo uns pelos outros.

O barroco determina a vida cotidiana como uma obra de arte. Percebe-se que, em cada grupo, em cada ambiente, em cada momento, há algo que convida para a saída temporária do "Eu" e se dilui no "Nós". Nesse instante, em que se abandonam, brevemente, as características de nossa "carteira de identidade", compreende-se a precariedade das nossas certezas habituais que fundamentam, de modo puramente egoísta, nossas decisões, pois se despreza o Outro como algo (ou alguém) estranho. Se os Direitos Humanos são incapazes de enxergar esses matizes, qual o seu propósito histórico e jurídico? Por esse motivo, quando a educação estimula a sensibilidade, especialmente jurídica, a partir da vida como obra de arte - barroca -, insiste-se:

A obra de arte barroca, quando permeada nos meios urbanos, opera segundo a sensação de se (re)viver aquele ritual ligado ao solo (ambiente) e resulta em efeitos sociais gerados pela reflexão da dinâmica entre o espaço e o tempo (acontecimento) porque a característica imagética exerce papel unificador desse querer estar-junto, dessa sedução (aparência). A repetição, o eterno retorno com o objetivo de se retardar o tempo que avança progressivamente, permite visualizar 
a teatralidade do cotidiano. Encena-se diversos papéis para manter o equilíbrio das relações inter-individuais e fomentar a idéia da organicidade que se constrói por meio da incorporação do elemento trágico e do segredo. Por que segredo? Em momento oportuno, afirmou-se que a teatralidade e o trágico criam uma imagem sedutora. Essa sedução ainda é desconhecida pela pessoa e a convida para descobrir o que há naquela aparência que se torna o objeto de sua afeição. O segredo e a teatralidade, para Maffesoli, parecem resumir o sentido de se apreciar o meio social como uma arte barroca porque se descobre como esse conjunto liga-se organicamente formando o urbanismo barroco. Eis a palavra na qual o barroco acentua o momento presente em oposição às deduções lineares da História; a oposição entre o sentido orgânico e mecânico: descobrimento. $\mathrm{O}$ ato de descobrir o segredo do cotidiano, mesclado pelo aspecto teatral e trágico, revela a diferença entre se querer construir a unidade social e se descobrir a unicidade que permeia o estar-junto (AQUINO, 2011, p. 55-56).

Os Direitos Humanos somente têm significado - histórico e jurídico - quando a vida for concebida como uma obra de arte na qual o ser estetizado, sensibilizado pelas diferentes e plurais matizes de sua composição, se indigna contra o injusto, o violento, o medíocre, o tedioso, o irresponsável, o sectário. Não é possível assegurar qualquer ambiente democrático sem que, no momento presente, a vivacidade barroca não se estimule, mais a mais, a transformar o insuportável em desejável por meio de seu significado utópico.

Essa é a função de uma educação para os Direitos Humanos crítica: insistir, apostar na resistência contra tudo que denigre o esclarecimento acerca da nossa humanidade na qual habita o Outro e promover o agir crítico a partir das utopias carregadas de esperança.

\section{CONCLUSÃO}

O estudo acerca do cenário da educação jurídica no Brasil denota que grande parte das Faculdades de Direito distanciaram-se do binômio qualidade-eficiência, transformando-o em lucratividade-institucional. O 
clima educacional, inerente às Instituições de Ensino, cedeu espaço para a instalação do legado empresarial, o qual visa, quase sempre, à competição, e ao lucro. O resultado desse (trágico) cenário é a massificação do Ensino Jurídico, ao estilo das linhas de montagem fordistas, bem como o desinteresse por aquilo que a educação traz como chance de reconhecer a necessidade de uma imersão sobre si.

A ruptura que se precisa realizar desse contexto é uma tarefa árdua e demasiadamente complexa, pois, quando o ensino conduz a pessoa para caminhos sempre facilitadores, quando compreende a realidade como fórmula puramente lógica, como se observa especialmente no pensamento acadêmico jurídico das Graduações, a educação não estimula o pensar diferente, não considera outros elementos constitutivos da natureza humana (emoções, percepções, sensibilidades) e pouco se viabiliza a fim de que Educação e Ensino cumpram a sua função social. Cria-se a ilusória ideia de que a manutenção de uma sociedade sadia e equilibrada se faz exclusivamente por meio da lei.

É necessário repensar e estruturar a educação jurídica sob pilares constituídos de verdades e realidades, ou seja, compreender o ambiente onde se vive e lançar-se na busca pela sua melhoria. Conhecer as mazelas sociais em sua dimensão mais ampla significa, primeiro, reconhecer as limitações da nossa natureza e condição humana para, após, identificar essas características no Outro. O Direito se constitui por relações humanas no cotidiano. É nesse espaço, esclarecido, antes, pela educação, que se desenvolve, se amplia e se consolida o nosso vínculo antropológico comum.

Acredita-se que a busca pela humanização do Direito será alcançada por meio de uma educação na qual sensibilize, provoque, traga a indignação contra as pessoas que passam fome, que sofrem intensas formas de violência (física, psicológica ou simbólica), que se desenvolvem em cená- 
rios de profunda miséria, que não possuem acesso aos serviços públicos mais indispensáveis a sua segurança e bem-estar, que não têm a chance de sequer envelhecer com dignidade, entre outros.

Provar, ouvir, tocar, compreender, sentir o intenso fluxo desse rio heraclitano chamado vida por meio das nossas sensações, da presença do Outro, demonstra como se torna necessário esclarecer, ao longo tempo, como o diálogo entre o "Eu”, o "Tu”, inseridos no "Mundo" - o qual estabelece, também, formas de comunicação com os seres humanos - irá constituir uma expressão cujo significado é, ainda, enigmático para todos: o "Nós".

Educar para os Direitos Humanos significa conhecer, conviver e mediar a pluralidade de "estranhezas" que se manifestam no mundo. Esse objetivo somente é possível quando o processo Educação e Ensino, sob o ângulo do Direito, estimulam a compreender os sentimentos, valores, emoções, pois, em cada um desses lugares de sentido, fomenta e possibilita a construção de novos contextos sociais, os quais devem ser estruturados a partir do conhecimento teórico e prático, sem que haja espaços para tendências neutras, indiferentes ou puramente metafísicas.

A educação para os Direitos Humanos somente acontece quando se promove inicialmente as melhorias necessárias para que cada pessoa tenha capacidade de agente, ou seja, de modificar o cenário no qual vive, pois esses terão condições para atuar na resolução dos conflitos. Parte-se da premissa de que o desprezo, a indiferença e a marginalização do Outro incita o ódio, a vingança, o assassinato, as guerras, a violência, entre outros. É no reconhecimento do Outro, nesse estar-junto-com-o-Outro-no-mundo, que se modificará, de modo mais profundo, nossas relações e, por consequência, nossos direitos. Essa educação esclarece como todos elaboram, diariamente, significados para tornar o discurso dos Direitos Humanos vivo e possível. 
Percebe-se, na nossa atual educação jurídica, uma intensa deformação, pois parte-se da errônea premissa de que as faculdades de Direito possuem o papel único de formar seus acadêmicos segundo preceitos da lei, da jurisprudência e (muito pouco ou nada) da doutrina. Entende-se que, quando uma pessoa é exposta a essas práticas de "produção em massa intelectual”, ao estilo daquilo que Chaplin já (d)enunciava em seu filme "Tempos Modernos", essa espera - na melhor descrição: ser passivo - recebe o conteúdo pronto, já formatado pelos docentes. Ela torna-se incapaz de construir seus próprios saberes críticos a partir de sua realidade cultural e comunitária, e se abstém de participar do jogo da convivência.

A partir de novos conhecimentos, como aqueles sugeridos por Warat, é possível vislumbrar metodologias de Educação e Ensino que transcendem a práxis comum, pois parte-se da premissa de que os sentidos fazem parte da arte de constituição dos saberes. Quando há proximidade e sensibilidade entre as pessoas, todos promovem uma Educação que permite ao Educando se tornar imune aos aspectos vampirescos que o rodeiam na Academia e suas “distorções”, como, por exemplo, nos casos em que a mídia não contribui com informações necessárias para o desvelo da educação e enfatiza os "crimes-show".

Esses aspectos que constituem um verdadeiro circo midiático e promovem a cultura do medo, afastam as pessoas da Socialidade, do convívio, e torna-os reféns de suas residências, as quais se transformam em verdadeiras prisões, protegidas por altos muros e sofisticados sistemas de segurança. Este comportamento assombrado intensifica uma postura excessivamente egoísta e cria a errônea ideia de proteção pela rápida e (moralmente) indolor eliminação do Outro.

Por esse motivo, a hipótese apresentada ao nosso problema de pesquisa se confirmou como negativa, pois, sem uma educação destinada a compreender diferentes culturas, valores e modos de convivência, é impossível exigir o cumprimento da paz almejada pelos Direitos Humanos. 
Somente uma Razão Sensível, que se manifesta no cotidiano de todos e se projeta como condição de vida digna, permite a viabilidade dessa histórica utopia carregada de esperança e, acrescente-se, esperanças sensatas.

Educar para os Direitos Humanos é deixar-se envolver pelo contexto em que se vive, ao se conhecer as roupagens e distorções do mundo da vida, ao se permitir conduzir pelas inquietudes e se manifestar contra as injustiças. Ao se vivenciar as adversidades de nosso cotidiano, ao se esclarecê-las por meio da educação, é possível traçar novas soluções que promovam o equilíbrio social, pois, nesse momento, os Direitos Humanos se tornam a práxis da nossa vida comum.

\section{REFERÊNCIAS}

AQUINO, Sérgio Ricardo Fernandes de. O direito em busca de sua humanidade: diálogos errantes. Curitiba: CRV, 2014.

. Rumo ao desconhecido: inquietações filosóficas e sociológicas sobre o direito na pós-modernidade. Itajaí, SC: Ed. da Universidade do Vale do Itajaí, 2011.

BAUMAN, Zygmunt; DONSKIS, Leonidas. Cegueira moral: a perda da sensibilidade na modernidade líquida. Tradução Carlos Alberto Medeiros. Rio de Janeiro: Zahar, 2014.

BITTAR, Eduardo C. B. Democracia, justiça e direitos humanos: estudos de teoria crítica e filosofia do direito. São Paulo: Saraiva, 2011.

. O direito na pós-modernidade: e reflexões frankfurtianas. 2. ed. Rio de Janeiro: Forense Universitária, 2009.

. Estudos sobre o ensino jurídico: pesquisa, metodologia, diálogo e cidadania. 2. ed. São Paulo: Atlas, 2006.

BOFF, Leonardo. Saber cuidar. ética do humano, compaixão pela terra. 15. ed. Petrópolis, RJ: Vozes, 2008. 
COCCIA, Emanuele. A vida sensivel. Tradução Diego Cervelin. Florianópolis: Cultura e Barbárie, 2010.

CUNHA, Paulo Ferreira da. A constituição viva: cidadania e direitos humanos. Porto Alegre: Livraria do Advogado, 2007.

DIAS, Maria da Graça dos Santos. Sociedade. In: BARRETO, Vicente de Paulo. Dicionário de filosofia política. São Leopoldo, RS: Ed. da Unisinos, 2010.

FRANCISCO. Laudato si: sobre o cuidado da casa comum. São Paulo: Paulus; Loyola, 2015.

FREIRE, Paulo. Pedagogia da autonomia: saberes necessários à prática educativa. 31. ed. São Paulo: Paz e Terra, 1996.

GRUBBA, Leilane Serratine; AQUINO, Sérgio Ricardo Fernandes de. Direitos humanos: o problema do contexto. Revista Direito e Política, Itajaí, SC, v. 10, n. 3, p. 1964. Disponível em: <http://www6.univali.br/seer/index.php/rdp/ article/view/8027/4575>. Acesso em: 5 set. 2015.

GRUBBA, Leilane Serratine. O essencialismo nos direitos humanos. Florianópolis: Empório do Direito, 2016.

HEGEL, Georg Wilhelm Friedrich. Linhas fundamentais da filosofia do direito: ou Direito natural e ciência do Estado em compêndio. Tradução Paulo Meneses e outros. São Leopoldo, RS: Ed. da Unisinos, 2010.

HESSEL, Stéphane. Indignai-vos! Tradução Marli Peres. São Paulo: Leya, 2011. HUSSERL, Edmund. La idea de la fenomenología: cinco leciones. Traducción Miguel García-Baró. 3. reimp. Madrid: Fondo de Cultura Económica, 2004. INWOOD, Michael. Dicionário de Hegel. Tradução Álvaro Cabral. Rio de Janeiro: Zahar, 1997.

KOSIK, Karel. Dialética do concreto. Tradução Célia Neves e Alderico Toríbio.3. ed. Rio de Janeiro: Paz e Terra, 1985.

LACROIX, Jean-Yves. A utopia: um convite à filosofia. Tradução Marcus Penchel. Rio de Janeiro: Jorge Zahar, 1996. 
LÉVINAS, Emmanuel. Totalidade e infinito. Tradução José Pinto Ribeiro. Lisboa: Edições 70, 2000.

MAFFESOLI, Michel. Elogio da razão sensivel. Tradução Albert Christophe Migueis Stuckenbruck. 4. ed. Petrópolis, RJ: Vozes, 2008.

Homo eroticus: comunhões emocionais. Tradução Abner Chiquieri. Rio de Janeiro: Forense, 2014.

No fundo das aparências. Tradução Bertha Halpern Gurovitz. 3. ed. Petrópolis, RJ: Vozes, 2005.

MANNHEIM, Karl. Ideologia e utopia. Tradução Sérgio Magalhães Santeiro. 4. ed. Rio de Janeiro: Zahar, 1982.

MELO, Osvaldo Ferreira de. Dicionário de política jurídica. Florianópolis: Ed. da $\mathrm{OAB} / \mathrm{SC}, 2000$.

MELO, Osvaldo Ferreira de. Fundamentos da política jurídica. Porto Alegre: Sergio Antonio Fabris, 1994.

PASOLD, Cesar Luiz. A função social do Estado contemporâneo. 4. ed. Itajaí, SC: Ed. da Univali, 2013.

Metodologia da pesquisa jurídica: teoria e prática. 12. ed. São Paulo: Conceito Editorial, 2011.

ROCHA, Leonel Severo. A aula mágica de Luis Alberto Warat: genealogia de uma pedagogia da sedução para o ensino do direito. Portal de e-governo, inclusão digital e sociedade do conhecimento. 2012. Disponível em: $<\mathrm{http}: / /$ www.egov.ufsc.br/portal/conteudo/aula-m\%C3\%A1gica-de-luis-alberto-warat-genealogia-de-uma-pedagogia-da-sedu\%C3\%A7\%C3\%A3o-para-o-ensino-do-d> . Acesso em: 10 set. 2015.

RODRIGUES, Horácio Wanderlei. O ensino do direito, os sonhos e as utopias. In: RODRIGUES, Horácio Wanderlei (Org.). Ensino jurídico para que $(m)$ ? Florianópolis: Fundação Boiteux, 2000.

ROSA, Alexandre Morais da. Guia compacto do processo penal conforme a teoria dos jogos. 2. ed. Rio de Janeiro: Lúmen Júris, 2014. 
SILVA, Moacyr Motta da. Direito e sensibilidade. In: DIAS, Maria da Graça dos Santos; MELO, Osvaldo Ferreira de; SILVA, Moacyr Motta da (Org.). Política jurídica e pós-modernidade. Florianópolis: Conceito, 2009.

STRECK, Lenio Luiz. Hermenêutica jurídica e $(m)$ crise: uma exploração hermenêutica da construção do Direito. 8. ed. Porto Alegre: Livraria do Advogado, 2009.

VASCONCELLOS, Celso dos S. Construção do conhecimento em sala de aula. 13. ed. São Paulo: Libertad, 2002.

WARAT, Luis Alberto. A ciência jurídica e seus dois maridos. 2. ed. Santa Cruz do Sul, RS: Edunisc, 1985.

A rua grita Dionísio! Direitos humanos de alteridade, surrealismo e cartografia. Tradução Vívian Alves de Assis, Julio Cesar Marcellino Júnior e Alexandre Morais da Rosa. Rio de Janeiro: Lúmen Júris, 2010.

. Epistemologia e ensino do direito: o sonho acabou. 2. ed. Florianópolis: Fundação Boiteux, 2004.

ZAMBAM, Neuro José; AQUINO, Sérgio Ricardo Fernandes de. Tolerância: reflexões filosóficas, políticas e jurídicas para o século XXI. Revista da Ajuris, Porto Alegre, v. 142, n. 137, p. 374, mar. 2015. Disponível em: <http://www. ajuris.org.br/OJS2/index.php/REVAJURIS/article/view/389/323>. Acesso em: 5 set. 2015.

Recebido em: $14 / 3 / 2016$

Revisões requeridas em: 14/6/2016

Aprovado em: 20/6/2016 